\title{
Clinical significance of the muscle-retracting sign during colorectal endoscopic submucosal dissection
}

Authors

Institutions
Takashi Toyonaga', Shinwa Tanaka', Mariko Man- $\mathrm{I}^{2}$, James East ${ }^{3}$, Wataru Ono ${ }^{4}$, Eisei Nishino ${ }^{5}$, Tsukasa Ishida ${ }^{6}$, Namiko Hoshi ${ }^{6}$, Yoshinori Morita ${ }^{6}$, Takeshi Azuma ${ }^{6}$

Institutions are listed at the end of article. submitted 3. October 2014 accepted after revision 31. October 2014

\section{Bibliography}

DOI http://dx.doi.org/

10.1055/s-0034-1391665

Published online: 5.5.2015

Endosc Int Open 2015; 03: E246-E251

(c) Georg Thieme Verlag KG Stuttgart · New York

E-ISSN 2196-9736

\section{Corresponding author}

Takashi Toyonaga, MD

Department of Endoscopy

Kobe University Hospital

7-5-1 Chuo-ku

Kusunoki-Cho

Kobe

Hyogo 650-0017

Japan

Fax: +81-78-382-6309

toyonaga@med.kobe-u.ac.jp
Background and study aims: During colorectal endoscopic submucosal dissection (ESD), the feature of a muscle layer being pulled toward a neoplastic tumor is sometimes detected. We call this feature the muscle-retracting sign (MR sign). The aim of this study was to evaluate whether the MR sign is associated with particular types of neoplastic lesions and whether it has any clinical significance for ESD sessions.

Patients and methods: A total of 329 patients underwent ESD for 357 colorectal neoplasms. The frequency of positivity for the MR sign was evaluated in different morphologic and histopathologic types of neoplasm. The success rate of complete resection and the incidence of complications were also evaluated according to whether lesions were positive or negative for the MR sign. Results: The rates of positivity for the MR sign in the various lesion types were as follows: laterally

\section{Introduction}

Endoscopic submucosal dissection (ESD) has enabled the en bloc resection of early-stage gastrointestinal tumors; this in turn has improved histopathologic assessments, making possible precise determinations of tumor margin and invasion [1 - 3]. The indications for colorectal ESD are (1) lesions larger than $20 \mathrm{~mm}$ in diameter, (2) lesions with scars due to previous endoscopic treatment or biopsy, (3) locally recurrent lesions after previous endoscopic or surgical resection, and (4) lesions predicted to be carcinoma with less than $1000 \mu \mathrm{m}$ of submucosal invasion from the muscularis mucosae before endoscopic treatment, according previous reports [4-6].

Improvements in diagnostic ability and endoscopic techniques, including magnified endoscopy and endoscopic ultrasound (EUS), have enabled a precise determination of the depth of invasion of most colorectal tumors $[7,8]$. The overall diagnostic accuracy of high-magnification co- spreading tumor-granular nodular mixed type (LST-G-M), 9.6\%; laterally spreading tumorgranular homogeneous type (LST-G-H) and laterally spreading tumor-nongranular type (LSTNG), $0 \%$; sessile type, $41.2 \%$. The resection rate was $100 \%(329 / 329)$ in lesions negative for the MR sign; however, it was 64.3\% (18/28) in lesions positive for the MR sign, which was significantly lower $(P<0.001)$.

Conclusions: The MR sign was present only in some protruding lesions, and more importantly, it was associated with a high risk of incomplete tumor removal by ESD. Our data indicate that lesions positive for the MR sign lesions should be dissected with great caution; alternatively, based on the features of the individual case, a switch to surgery should be considered for the benefit of the patient.

lonoscopy (HMC) for the differentiation of neoplastic colorectal lesions was $86 \%$ to $96 \%[9,10]$, and the sensitivity and specificity of HMC observation for the differentiation of intramucosal or submucosal superficial invasion $(<1000 \mu \mathrm{m})$ from submucosal deep invasion $(\geq 1000 \mu \mathrm{m})$ were $85 \%$ and $99 \%$, respectively [11]. In addition, the accuracy for differentiating small colorectal non-neoplastic polyps from neoplastic polyps and the accuracy for differentiating intramucosal or submucosal superficial invasion from submucosal deep invasion by narrow-band imaging magnifying observation were $92.3 \%$ and $87.7 \%$, respectively [12-14]. By EUS observation, the sensitivity and the specificity for differentiating intramucosal or submucosal superficial invasion from submucosal deep invasion was $71 \%$ [15]. However, there are always some difficult cases, especially those with large, protruding tumors. The pit pattern does not often reflect the pathologic change of deep tissue at the nodular area. Furthermore, it is difficult to delineate the deep 
tissue structure with EUS because of the attenuation of ultrasound. Therefore, diagnostic ESD is necessary with these lesions. During the ESD procedure, some colorectal neoplastic lesions exhibit an interesting feature in which the muscle layer under the tumor appears to be drawn by the neoplasm. We named this feature the muscle-retracting (MR) sign and wondered whether it might be of clinical relevance. To this end, we evaluated the frequency of lesions positive for the MR sign to investigate whether particular types of neoplastic lesion manifest this feature, and whether the MR sign has any clinical significance that might be helpful during ESD sessions.

\section{Patients and methods \\ $\nabla$}

\section{Patients and tumor assessment}

From June 2002 through June 2007, a total of 357 colorectal neoplasms in 329 patients were treated with ESD. The procedures were performed by one skilled endoscopist (T. T.), with experience in more than 1500 cases of lesion staging and ESD at Kishiwada Tokushukai Hospital, Kishiwada, Japan. The indications for ESD were (1) lesions larger than $20 \mathrm{~mm}$ in diameter, (2) lesions with scars due to previous endoscopic treatment or biopsy, (3) locally recurrent lesions after previous endoscopic or surgical resection, and (4) lesions predicted to be carcinoma with less than $1000 \mu \mathrm{m}$ of submucosal invasion from the muscularis mucosae before endoscopic treatment. The lesions were evaluated by observation under white light, observation after spraying with indigo carmine, and observation of the pit pattern with chromoendoscopy. All lesions and patients in whom colorectal ESD was performed were included in the study. Information on the clinicopathologic findings and procedural details of the ESD was collected from the medical records of each patient. Before endoscopic treatment, all patients gave written informed consent after the possible risks and complications of the procedures, anticipated results, and alternative approaches, including surgery, had been explained. The study protocol was approved by the ethics committee of Kishiwada Tokushukai Hospital.

\section{ESD procedure}

The FlexKnife (KD-630L; Olympus, Tokyo, Japan) and the FlushKnife (DK-2618JN; Fujifilm, Tokyo, Japan) were used from May 2002 to June 2005 and after June 2005, respectively. A conventional needle knife (KD-10Q-1, Olympus), a hook knife (KD620LR, Olympus), and the ST hood (DH-16CR, Fujinon) were used as ancillary devices. A single-channel endoscope (CF 240I, Olympus) was used with a 4-mm-long transparent hood to maintain a clear operating field. An electrosurgical generator, ICC 200, VIO 300 D (Erbe Elektromedizin, Tübingen, Germany), was also used.

The resected specimens were collected intact, stretched and pinned, fixed in formalin, sliced into 2-mm sections, and assessed microscopically. Histopathologic diagnosis was based on the Vienna classification. An sm1 cancer was defined as a minute submucosal cancer $(<1000 \mu \mathrm{m})$, and an sm2 cancer was defined as a submucosal deep cancer ( $\geq 1000 \mu \mathrm{m})$. After thorough pathologic assessment, if the lesion was resected en bloc, the treatment was considered an en bloc resection, and if the lesion was resected en bloc with margins negative for neoplasm, it was considered an en bloc R0 resection.

\section{Muscle-retracting sign}

Two cases representative of laterally spreading tumor-granular nodular mixed type (LST-G-M), which exhibited the MR sign under large nodules during ESD, are shown in $\bullet$ Fig. $\mathbf{1 a}$, b and - Fig. 2a, b. The MR sign is defined as the appearance of the muscle layer under a colorectal tumor being drawn by the tumor to form a triangular shape during ESD ( $\bullet$ Fig. 1c, d and $\bullet$ Fig. 2 c, d). We retrospectively divided dissected lesions into those positive for the MR sign, or MR(+), and those negative for the MR sign, or $\operatorname{MR}(-)$, and evaluated them for their clinicopathologic features, resection rates, en bloc $\mathrm{R} 0$ resection rates, and occurrence of complications. The presence of the MR sign was determined by two of the authors (S.T. and T. I.), who reviewed the ESD videos of enrolled patients.

\section{Complications}

Postoperative bleeding was defined when any of the following events were recorded: (1) requirement for endoscopic hemostatic treatment, (2) reduction of total hemoglobin by more than $2 \mathrm{~g} /$ $\mathrm{dL}$ compared with the last preoperative level, or (3) massive melena after ESD with no other apparent source of bleeding [16]. Perforation was diagnosed by the endoscopic finding of a hole forming all the way through the intestinal wall during endoscopic treatment, or by the presence of free air on abdominal plain radiography or computed tomography.

\section{Statistical analysis}

Statistical analysis was conducted with SPSS 18.0 (SPSS, Chicago, Illinois, USA). Proportions of categorical variables were compared with the two-sided Fisher's exact test and chi-squared test. A $P$ value of less than 0.05 was considered statistically significant.

\section{Results}

$\nabla$

The characteristics of 357 lesions in 329 patients who underwent ESD for colorectal neoplasm are shown in $\bullet$ Table 1. The male-tofemale ratio was 1.32 (189:140), and the median (range) age of the patients was $68(20-92)$ years. The locations of the lesions were as follows: rectum, 104; sigmoid colon-descending colon, 73; transverse colon-cecum, 180.The median (range) tumor size was $30(6-158) \mathrm{mm}$. The cases included 100 adenomas and 257 cancerous lesions: 184 mucosal cancers, 27 sm1 cancers, and $46 \mathrm{sm} 2$ cancers.

- Table 2 summarizes the correlations between the MR sign and the features of the patients and lesions. No significant differences were found between $\mathrm{MR}(+)$ lesions and $\mathrm{MR}(-)$ lesions in regard to patient sex, patient age, and tumor size. In terms of morphologic type, positivity for the MR sign was found only in protruding lesions, such as the LST-G-M and sessile type. The rate of positivity for the MR sign was significantly higher in the LST-G-M and sessile type $(P<0.05)$. In terms of localization, a trend was noted for $\mathrm{MR}(+)$ to be found in the rectum, but it did not reach statistical significance. In terms of histology, about half of submucosal massive cancer lesions exhibited the MR sign during ESD; on the other hand, more than $95 \%$ of benign and submucosal slight cancer lesions showed no MR sign.

To clarify whether this sign has any clinical relevance that might help in an assessment of the likelihood of successful ESD, we analyzed the clinical outcome of each case according to the presence or absence of the MR sign ( Table 3 ). The en bloc resection rate of $\operatorname{MR}(-)$ lesions was $100 \%$ (329/329) but was $64.3 \%(18 / 28)$ 

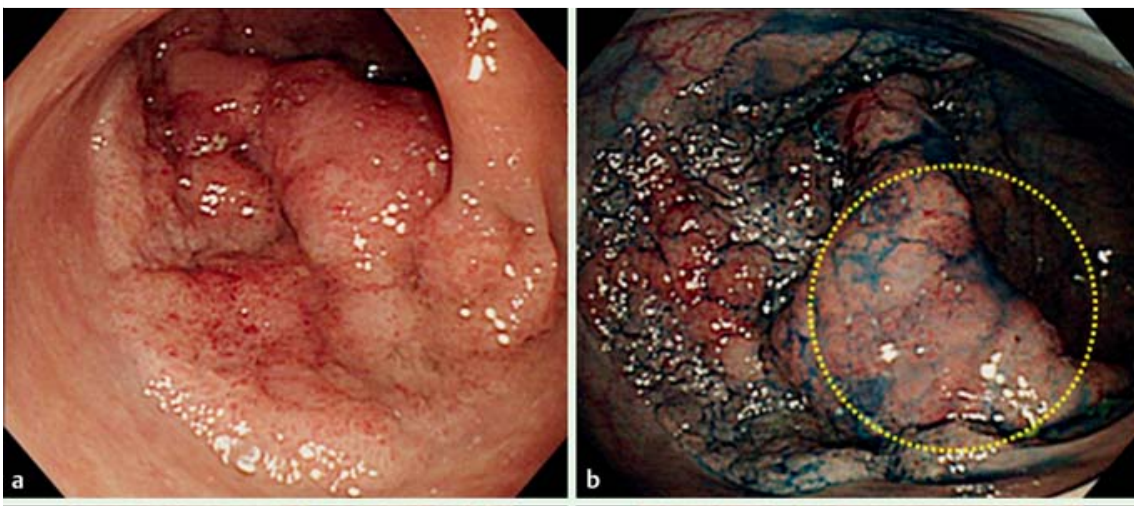

Fig. 1 Laterally spreading tumor of the granular nodular mixed type in the sigmoid colon $(\mathbf{a}, \mathbf{b})$. In the nodular area (within the yellow circle in $\mathbf{b}$ ), the muscle layer is retracted toward the tumor to form a triangular shape (MR sign; red arrows in $\mathbf{c}$ and $\mathbf{d}$ ). Histologic findings associated with the MR sign include severe fibrosis in the submucosal layer and retraction of muscularis propria (e).
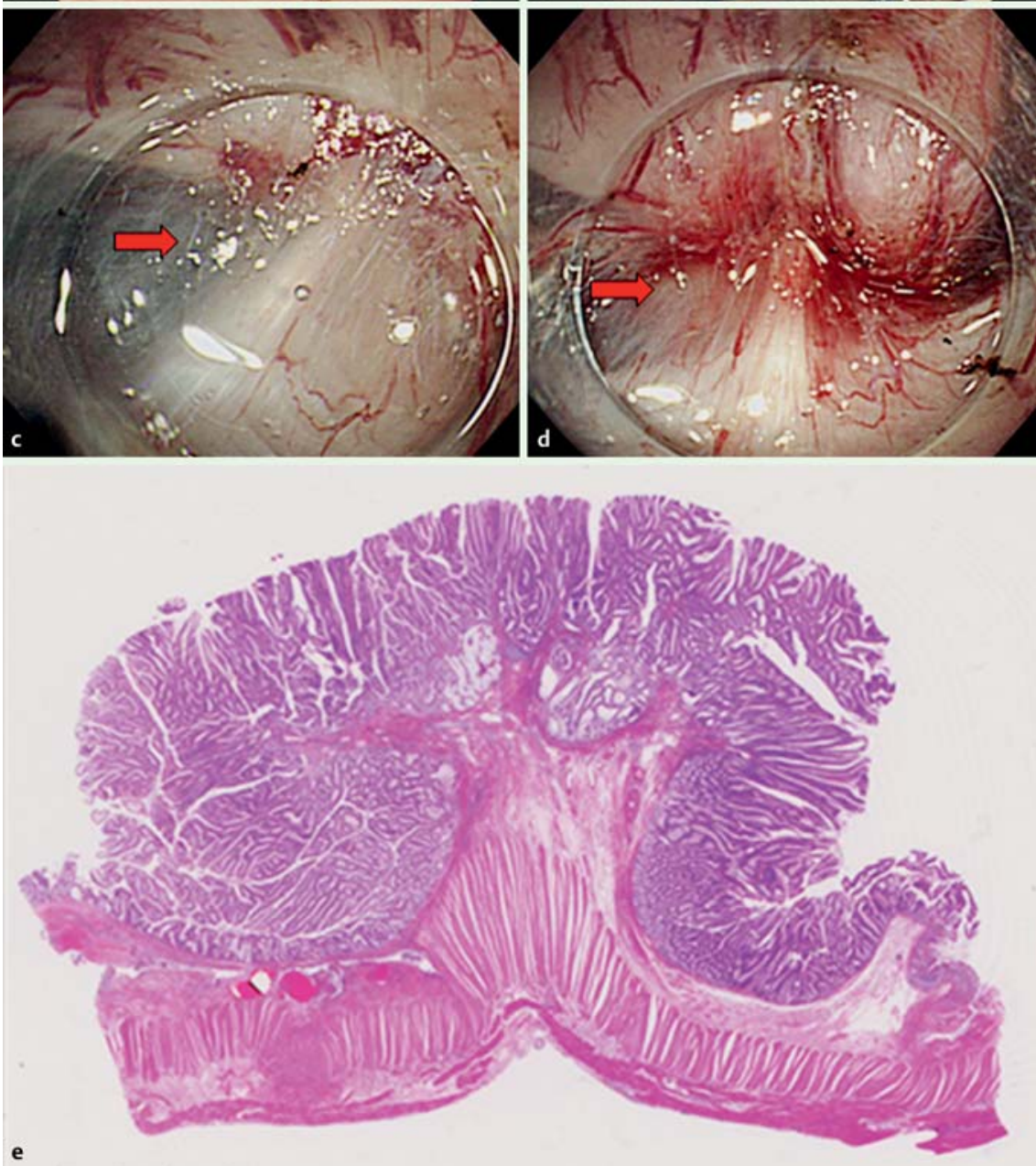

in $\mathrm{MR}(+)$ lesions, which was a statistically significant difference $(P<0.001)$. In all MR $(+)$ lesions, fibrosis had developed underneath the tumor in the submucosa, as confirmed by histologic evaluation ( $\bullet$ Fig. 1 e and $\bullet$ Fig. 2e). The patients with these lesions underwent surgery to ensure safe and complete removal of the tumor; ESD had to be aborted because the lesions were not resectable with this approach. All $\mathrm{MR}(+)$ lesions for which the therapeutic strategy was switched from ESD to surgery showed retraction of the muscularis propria layer by the tumor on histology ( $\bullet$ Fig. 1e and $\bullet$ Fig. 2e), suggesting that this histologic finding reflects the MR sign during ESD.

In addition, among the resected cases, the en bloc R0 resection rates were $98.2 \%(323 / 329)$ in $\mathrm{MR}(-)$ lesions and $77.8 \%(14 / 18)$ in $\operatorname{MR}(+)$ lesions, also a statistically significant difference $(P<$ $0.001)$.
In terms of complications, the postoperative bleeding rates and perforation rates were assessed. The rates of bleeding were $0.91 \%$ $(3 / 329)$ and $5.6 \%(1 / 18)$ and those of perforation were $1.8 \%$ $(6 / 329)$ and $5.6 \%(1 / 18)$ for $\mathrm{MR}(-)$ and $\mathrm{MR}(+)$ lesions, respectively. The differences between these rates were not statistically significant.

\section{Discussion}

$\nabla$

The opportunities for the endoscopic resection of large, protruding lesions are increasing because of the prevalence of colorectal ESD. Some lesions can be completely resected relatively easily; however, we have noticed that some lesions with the MR sign are extremely difficult to resect. 

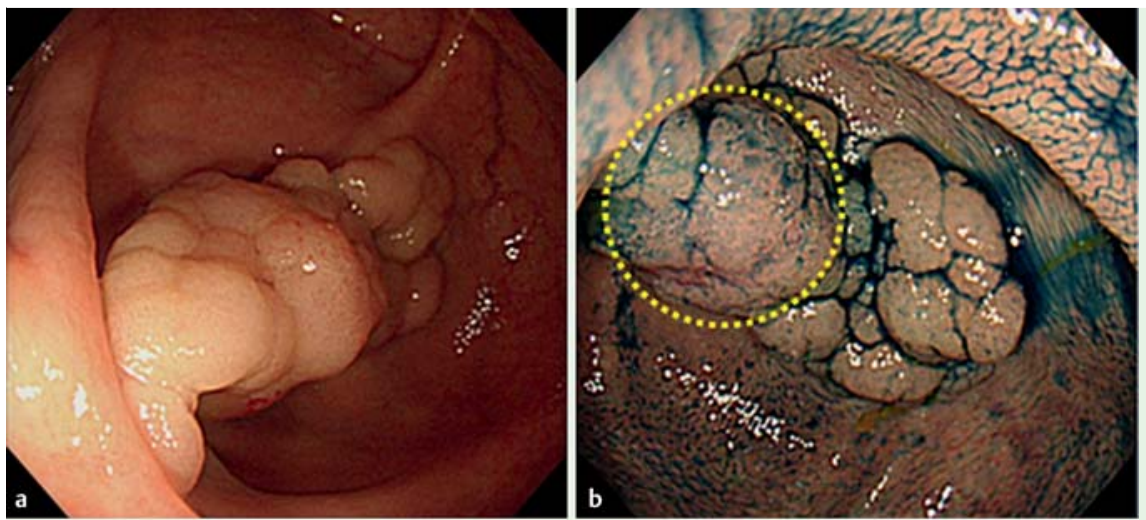

Fig. 2 Laterally spreading tumor of the granular nodular mixed type in the sigmoid colon $(\mathbf{a}, \mathbf{b})$. In the nodular area (within the yellow circle in $\mathbf{b}$ ), endoscopic submucosal dissection shows that the muscle layer is pulled upward toward the tumor (muscle-retracting sign; red arrows in $\mathbf{c}$ and $\mathbf{d}$ ). Histologic findings include retraction of the
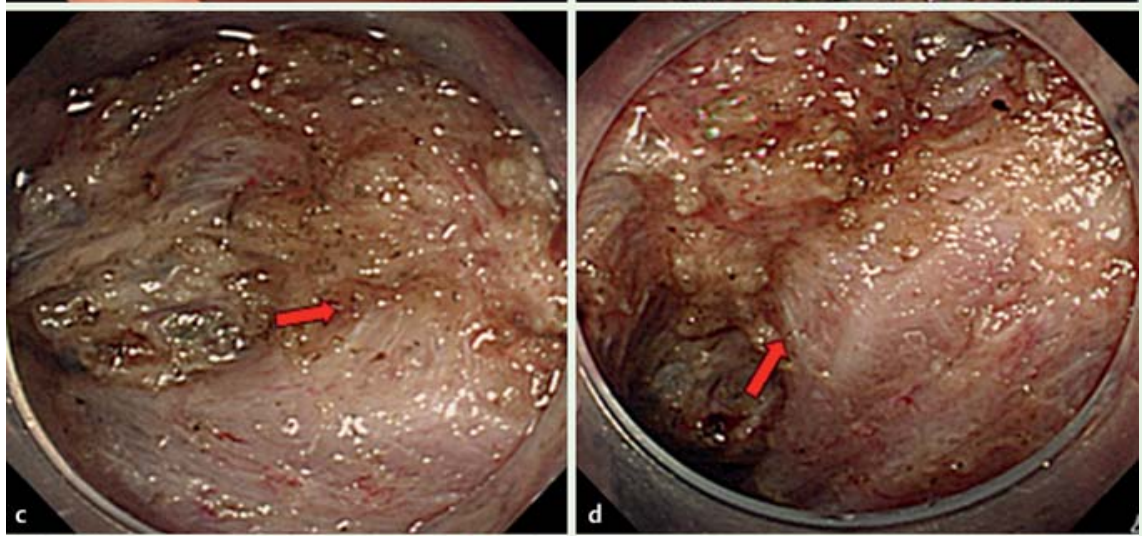

muscularis propria layer by the tumor (e).

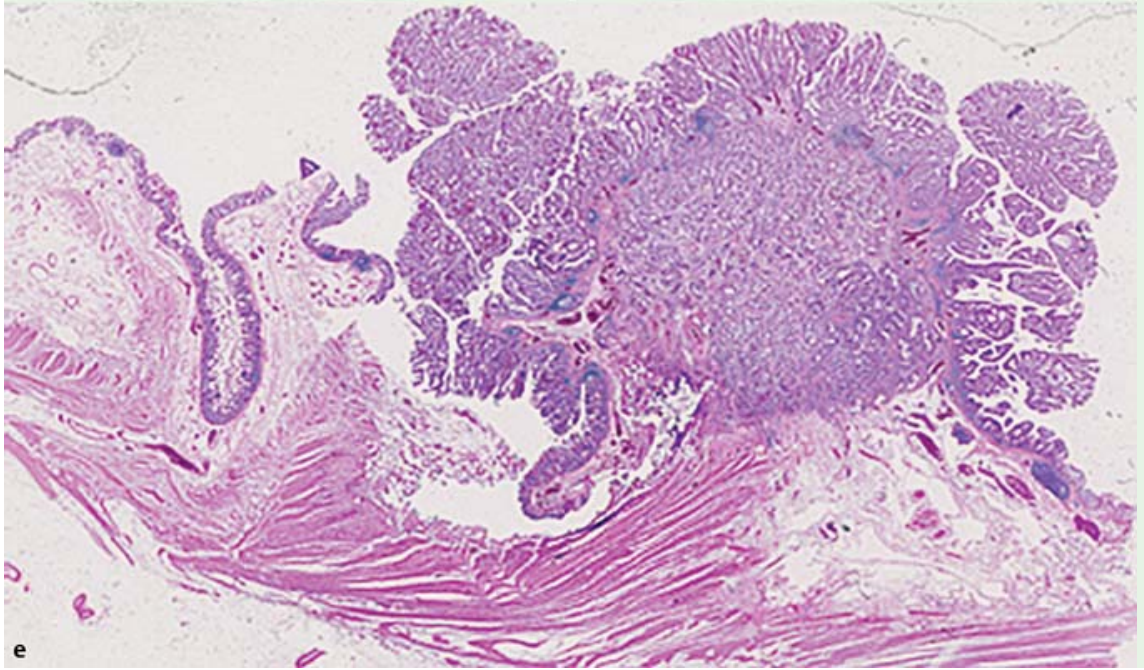

To determine the depth of invasion, evaluations of pit patterns and the results of barium enema examination and EUS are useful $[7,8,17,18]$. However, it is generally difficult to evaluate large, protruding lesions [19] because there is no feature or sign on barium enema examination that definitively indicates submucosal invasion, and the pathology of submucosal massive invasion is not often reflected in the superficial pit patterns. Moreover, it is difficult to delineate the deep tissue structure by EUS because of the attenuation of ultrasound [20].

There are two possible factors to explain the mechanism by which the MR sign develops. One is the desmoplastic reaction to cancer invasion, and the other is fibrosis caused by the mechanical force generated between the submucosa and the muscle layer as a result of intestinal peristalsis. Flat tumors are aligned horizontally to the muscle layer, so they are not pulled by peristalsis; however, a protruding lesion may easily be caught and pulled by peristalsis, which can generate an upward force and stress, leading to the development of fibrosis between the submucosa and muscle layer. This hypothesis is supported by the observation that among the tumors that we analyzed, all of the $\operatorname{MR}(+)$ lesions, including adenomas, mucosal cancers, and submucosal slight cancers, tended to have large nodules on their surface ( Fig.1a, b and $\bullet$ Fig. 2a, b); however, elucidation of the precise mechanism involved requires further investigation. The difference between the MR sign and submucosal fibrosis is that the MR sign involves the retraction of the muscularis propria layer with submucosal fibrosis. It is not easy to remove tumors with submucosal fibrosis, yet removal can still be accomplished by ESD if the depth of the dissection line is appropriately set and maintained during the procedure. On the other hand, the removal of lesions with the MR sign involves not only submucosal fibrosis but also an uneven dissection line due to muscle layer 
Table 1 Characteristics of 357 lesions in 329 patients who underwent endoscopic submucosal dissection (ESD) for colorectal neoplasm, subsequently correlated with presence or absence of the muscle-retracting sign.

\begin{tabular}{|l|l|}
\hline Patients, $\mathbf{n}$ & 329 \\
\hline Lesions, $\mathrm{n}$ & 357 \\
\hline Sex, $\mathrm{n}$ & \\
\hline Male & 189 \\
\hline Female & 140 \\
\hline Median age (range), $\mathrm{y}$ & $68(20-92)$ \\
\hline Location, $\mathrm{n}$ & \\
\hline Rectum & 104 \\
\hline S-D & 73 \\
\hline T-C & 180 \\
\hline Morphologic type, $\mathrm{n}$ & \\
\hline LST-G-M & 146 \\
\hline LST-G-H & 53 \\
\hline LST-NG-F & 104 \\
\hline LST-NG-P & 20 \\
\hline Sessile & 34 \\
\hline Median tumor size (range), mm & $30(6-158)$ \\
\hline Tumor depth, $\mathrm{n}$ & 100 \\
\hline Adenoma & 184 \\
\hline Mucosal cancer & 27 \\
\hline sm1 cancer & 46 \\
\hline sm2 cancer & \\
\hline
\end{tabular}

S-D, sigmoid colon-descending colon; T-C, transverse colon-cecum; LST-G-M, laterally spreading tumor - granular nodular mixed type; LST-G-H, laterally spreading tumor-granular homogeneous type; LST-NG-F, laterally spreading tumornongranular flat elevated type; LST-NG-P, laterally spreading tumor-nongranular pseudo-depressed type; sm1 cancer, minute submucosal cancer $(<1000 \mu \mathrm{m})$; sm2 cancer, submucosal deep cancer $(\geq 1000 \mu \mathrm{m})$.

Table 2 Correlation of features of patients and lesions with muscle-retracting (MR) sign.

\begin{tabular}{|c|c|c|c|}
\hline & $M R(+)$ & MR(-) & $P$ value \\
\hline \multicolumn{4}{|l|}{ Sex, n } \\
\hline Male & 14 & 175 & 0.26 \\
\hline Female & 14 & 126 & \\
\hline Median age (range), y & $62(45-81)$ & $68(20-92)$ & 0.09 \\
\hline \multicolumn{4}{|l|}{ Morphologic type, n } \\
\hline LST-G-M & 14 & 132 & 0.01 \\
\hline LST-G-H & 0 & 53 & $<0.001$ \\
\hline LST-NG-F & 0 & 104 & $<0.001$ \\
\hline LST-NG-P & 0 & 20 & $<0.001$ \\
\hline Sessile & 14 & 20 & $<0.001$ \\
\hline \multicolumn{4}{|l|}{ Location, $\mathrm{n}$} \\
\hline Rectum & 18 & 86 & $<0.001$ \\
\hline S-D & 6 & 67 & 0.53 \\
\hline $\mathrm{T}-\mathrm{C}$ & 4 & 176 & $<0.001$ \\
\hline $\begin{array}{l}\text { Median tumor size } \\
\text { (range), mm }\end{array}$ & $29(10-155)$ & $30(6-133)$ & 0.98 \\
\hline \multicolumn{4}{|l|}{ Tumor depth, $\mathrm{n}$} \\
\hline Adenoma & 1 & 99 & 0.01 \\
\hline Mucosal cancer & 5 & 179 & $<0.001$ \\
\hline sm1 cancer & 1 & 26 & 0.35 \\
\hline sm2 cancer & 21 & 25 & $<0.001$ \\
\hline
\end{tabular}

$M R(+)$, MR sign positive; MR(-), MR sign negative; LST-G-M, laterally spreading tumor-granular nodular mixed type; LST-G-H, laterally spreading tumor-granular homogeneous type; LST-NG-F, laterally spreading tumor-nongranular flat elevated type; LST-NG-P, laterally spreading tumor-nongranular pseudo-depressed type; S-D, sigmoid colon - descending colon; T-C, transverse colon-cecum; sm1 cancer, minute submucosal cancer $(<1000 \mu \mathrm{m})$; sm2 cancer, submucosal deep cancer $(\geq 1000 \mu \mathrm{m})$.
Table 3 Comparison of clinical outcomes by muscle-retracting (MR) sign.

\begin{tabular}{|llll|} 
& MR(+) & MR(-) & P value \\
\hline $\begin{array}{l}\text { En bloc resection } \\
\text { rate, \% }\end{array}$ & $64.3(18 / 28)$ & $100(329 / 329)$ & $<0.001^{1}$ \\
\hline $\begin{array}{l}\text { En bloc R0 resection } \\
\text { rate, \% }\end{array}$ & $77.8(14 / 18)$ & $98.2(323 / 329)$ & $<0.001^{1}$ \\
\hline $\begin{array}{l}\text { Postoperative bleeding } \\
\text { rate, \% }\end{array}$ & $5.6(1 / 18)$ & $0.91(3 / 329)$ & $0.19^{2}$ \\
\hline \begin{tabular}{l} 
Perforation rate, \% \\
\hline
\end{tabular} & $5.6(1 / 18)$ & $1.8(6 / 329)$ & $0.31^{2}$ \\
\hline
\end{tabular}

$\mathrm{MR}(+)$, MR sign positive; MR(-), MR sign negative.

${ }^{1}$ The data were evaluated with the chi-squared test.

2 The data were evaluated with the Fisher's exact test as appropriate.

retraction, which can increase the risk of adverse events. Furthermore, it is difficult to use proper counter-traction, which makes it even more difficult to complete the dissection.

In terms of complications, there were no statistically significant differences between two groups. This suggests that the MR sign would not increase the risk of these complications; however, we must note that this result should be interpreted carefully because ESD sessions were aborted for some MR(+) lesions to avoid complications and ensure safe treatment.

In our study, we had to abort ESD in 10 patients with MR(+) lesions in order to avoid perforation, so the rate of complications could have been higher than the rate in our present data if ESD had been continued. The en bloc resection rate was significantly lower for $\operatorname{MR}(+)$ lesions. This was presumably due to severe fibrosis with muscle layer retraction under the large nodular areas, which made distinguishing the submucosal layer from the muscle layer difficult.

Our data suggest that the MR sign is useful to optimize selection of the therapeutic strategy for each patient. If the MR sign is found in a rectal lesion, the endoscopist should first try to continue ESD to avoid permanent colostomy. However, if the tumor is in the colon, ESD should be discontinued and surgery (partial colectomy) should be selected to ensure complete removal of the tumor without loss of the function of the large intestine.

It is difficult to predict the presence of the MR sign before endoscopic treatment. There are limitations to doing it perfectly, and it is not rare for operators to encounter some unexpected difficulties during the procedure. The purpose of this paper is to report that the MR sign, which cannot be detected before but only during a procedure, might be useful to predict the technical difficulties of continuing ESD. Our data indicate that some tumors, especially large lesions with protruding areas, exhibit the MR sign and that others do not, even they are morphologically similar. Because $\operatorname{MR}(-)$ lesions can be treated by ESD without many complications or difficulties, it is not practical to treat all these lesions surgically. As we continue to try to find a new strategy to somehow detect the MR sign before endoscopic treatment, it is important that endoscopic instruments be developed that can safely resect $\mathrm{MR}(+)$ lesions.

There are some limitations to this study. It is a retrospective, single-center study, and the two reviewers (S.T. and T. I.) were not blinded to some of the ESD results. Further prospective studies at multiple institutions are warranted to verify the clinical significance of the MR sign.

In conclusion, the MR sign is an indication of difficult ESD with a risk of resection failure. Therefore, we suggest that detection of the MR sign during ESD may be useful for selecting the appropri- 
ate treatment - namely, continued ESD or surgery - to achieve the best result for each case and avoid unwanted outcomes.

\section{Competing interests: None}

\section{Institutions}

${ }^{1}$ Department of Endoscopy, Kobe University Hospital, Kobe, Japan

${ }^{2}$ Division of Upper Gastrointestinal Tract, Department of Surgery, Fujita Health

University, Aichi, Japan

3 Translational Gastroenterology Unit, John Radcliffe Hospital, Oxford, United Kingdom

${ }^{4}$ Department of Gastroenterology, Kishiwada Tokushukai Hospital, Kishiwada, Japan

${ }^{5}$ Department of Pathology, Kishiwada Tokushukai Hospital, Kishiwada, Japan

${ }^{6}$ Division of Gastroenterology, Department of Internal Medicine, Graduate

School of Medicine, Kobe University, Kobe, Japan

\section{References}

1 Tanaka S, Oka S, Kaneko I et al. Endoscopic submucosal dissection for colorectal neoplasia: possibility of standardization. Gastrointest Endosc 2007; 66: 100-107

2 Saito Y, Uraoka T, Yamaguchi Yet al. A prospective, multicenter study of 1111 colorectal endoscopic submucosal dissections (with video). Gastrointest Endosc 2010; 72: 1217-1225

3 Toyonaga T, Man-i M, Fujita T et al. Retrospective study of technical aspects and complications of endoscopic submucosal dissection for laterally spreading tumors of the colorectum. Endoscopy 2010; 42: $714-722$

4 Tanaka S, Oka S, Chayama K. Colorectal endoscopic submucosal dissection: present status and future perspective, including its differentiation from endoscopic mucosal resection. J Gastroenterol 2008; 43: $641-651$

5 Tanaka S, Terasaki M, Kanao H et al. Current status and future perspectives of endoscopic submucosal dissection for colorectal tumors. Dig Endosc 2012; 24: $73-79$

6 Tanaka S, Tamegai Y, Tsuda $S$ et al. Multicenter questionnaire survey on the current situation of colorectal endoscopic submucosal dissection in Japan. Dig Endosc 2010; 22: 012-S8

7 Huang Q Fukami N, Takeuchi T et al. Interobserver and intra-observer consistency in the endoscopic assessment of colonic pit patterns. Gastrointest Endosc 2004; 60: 520-526
8 Stergiou N, Haji-Kermani N, Schneider C et al. Staging of colonic neoplasms by colonoscopic miniprobe ultrasonography. Int J Colorectal Dis 2003; 18: 445 - 449

9 Togashi K, Konishi F, Ishizuka T et al. Efficacy of magnifying endoscopy in differential diagnosis of neoplastic and non-neoplastic polyps of large bowel. Dis Colon Rectum 1999; 42: 1602 - 1608

10 Liu HH, Kudo SE, Juch JP. Pit pattern analysis by magnifying chromoendoscopy for the diagnosis of colorectal polyps. J Formos Med Assoc 2003; 102: $178-182$

11 Fujii T, Matsuda T. Chromoendoscopic and magnifying observation for colorectal submucosal carcinoma [in Japanese]. Gastroenterol Surg 2005; 28: 659-665

12 Sano Y, Ikematsu $\mathrm{H}, \mathrm{Fu} \mathrm{K}$ et al. Meshed capillary vessels by use of narrow-band imaging for differential diagnosis of small colorectal polyps. Gastrointest Endosc 2009; 69: 278-283

13 Katagiri A, Fu K, Sano $Y$ et al. Narrow band imaging with magnifying colonoscopy as diagnostic tool for predicting histology of early colorectal neoplasia. Aliment Pharmacol Ther 2008; 27: 1269-1274

14 Ikematsu $H$, Matsuda T, Emura $F$ et al. Efficacy of capillary pattern type IIIA/IIIB by magnifying narrow band imaging for estimating depth of invasion of early colorectal neoplasms. BMC Gastroenterol 2010; 10 : 33

15 Shimura T, Ebi M, Yamada T et al. Magnifying chromoendoscopy and endoscopic ultrasonography measure invasion depth of early stage colorectal cancer with equal accuracy on the basis of a prospective trial. Clin Gastroenterol Hepatol 2014; 12: 662-668

16 Tajiri H, Kitano S. Complications associated with endoscopic mucosal resection: definition of bleeding that can be viewed as accidental. Dig Endosc 2004; 16: 134-S136

17 Ott DJ, Gelfand $D W, W u$ WC et al. Colon polyp morphology on doublecontrast barium enema: its pathologic predictive value. AJR Am J Roentgenol 1983; 141: 965 - 970

18 Ikehara H, Saito Y, Matsuda T et al. Diagnosis of depth of invasion for early colorectal cancer using magnifying colonoscopy. J Gastroenterol Hepatol 2010; 25: $905-912$

19 Kobayashi K, Mukae M, Ogawa T et al. Benefits and risks associated with cutoff values of invasion depth of $1,000 \mu \mathrm{m}$ in patients with colorectal submucosal cancer. Intestine 2012; 16: 130-135 (in Japanese with English abstract)

20 Saitoh Y, Obara T, Einami K et al. Efficacy of high-frequency ultrasound probes for the preoperative staging of invasion depth in flat and depressed colorectal tumors. Gastrointest Endosc 1996; 44: $34-39$ 